\title{
East Asian Economic Growth-An Evolutionary Perspective
}

\section{Fariba Hashemi}

Swiss Federal Institute of Technology, Lausanne, Switzerland.

Email: Fariba.Hashemi@epfl.ch

Received June 27 $7^{\text {th }}, 2011$; revised August $2^{\text {nd }}, 2011$; accepted August $18^{\text {th }}, 2011$.

\begin{abstract}
The High Performing Asian Economies have been the fastest growing economies anywhere, anytime. This phenomenal growth experience has stimulated extensive research on its determinants. What is less known however, is dynamics of the distribution of income. This paper considers a statistical model to describe convergence of cross-country incomes across the High Performing Asian Economies. The empirical results illustrate that diffusion is a potential technique for the analysis of spatial dynamics of economic growth.
\end{abstract}

Keywords: East Asian Economic Growth, Evolutionary Perspective

\section{Introduction}

The High-Performing Asian Economies (HPAE) have been the fastest growing economies anywhere, anytime ${ }^{1}$. Figure 1 and Table 1 illustrate the strong economic growth which spread like a wave over the region between the years of 1960-1995.

Compared to large parts of Asia, Africa and Latin America, the High Performing Asian Economies have been unusually successful at achieving high growth rates. At the same time that the HPAE were growing at over $5.5 \%$, richer industrial economies were growing at around 2\%, South Asia likewise at 2\%, and Latin America at $1 \%$. Africa and the Middle East were shrinking ${ }^{2}$. The phenomenal growth in HPAE altered the global economic balance and contributed to closing of the economic gap between the OECD and developing countries.

The growth experience of East Asia has stimulated extensive research on its determinants [1-5]. Much attention has been devoted to the explanation of the shape of the distribution of income in the region by reference to steady state arguments. What is less known however, is the dynamics in question. To fill this gap, the present paper examines the dynamics in the cross-sectional distribution of income in High Performing Asian Economies.

\footnotetext{
${ }^{1}$ For purposes of this paper, High Performing Asian Economies include: China, Hong Kong, Indonesia, Japan, Malaysia, South Korea, Singapore, Taiwan, and Thailand.

${ }^{2}$ These figures are annual averages, based on GDP per person, 1965-1996. The author acknowledges and thanks Mark Hannay for assistance in the estimation section of this paper.
}

Income per person as a percentage of that in United States*

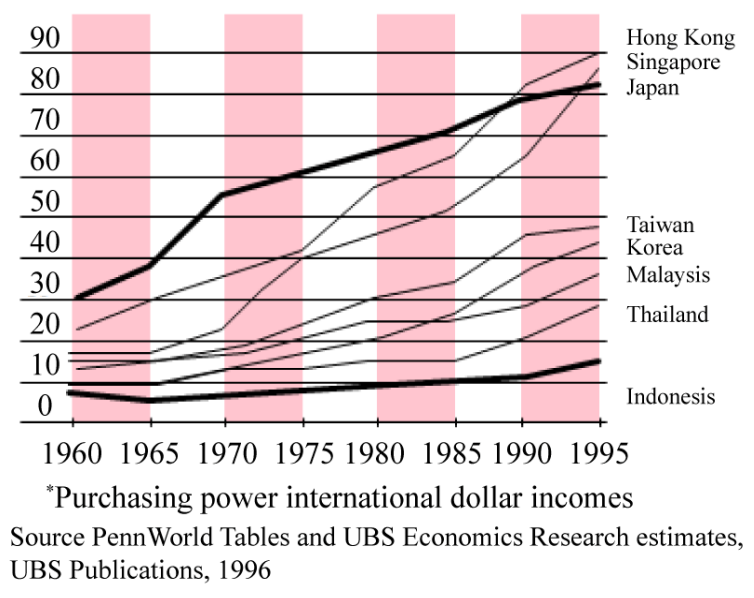

Figure 1. Strong economic growth spread like a wave over Asia.

\section{The Model}

Consider a region consisting of countries with different levels of income. The set of country incomes forms a long-run distribution which evolves over time. Assume that the dynamics of this distribution rely on two counteracting forces: 1) a mean-reversion process along time, driven by mobility of factors of production [6]; and 2) a diffusion process across regions, driven by search and learning [7-9]. 
Table 1. Asian economic growth.

\begin{tabular}{|c|c|c|c|c|}
\hline \multicolumn{5}{|c|}{ (Average Real GDP Percent Per Annum) } \\
\hline & 1960-1969 & 1970-1979 & 1980-1989 & 1990-1995 \\
\hline \multicolumn{5}{|l|}{ East Asia } \\
\hline Japan & 10.5 & 5.2 & 3.8 & 1.9 \\
\hline \multicolumn{5}{|c|}{ Asian "Tigers" } \\
\hline Hong Kong & - & 7.9 & 3.0 & 5.1 \\
\hline Korea & 7.7 & 9.4 & 8.1 & 7.9 \\
\hline Taiwan & 9.8 & 10.2 & 8.1 & 6.4 \\
\hline Singapore & - & 9.5 & 7.4 & 8.6 \\
\hline \multicolumn{5}{|c|}{ Other high growth ${ }^{*}$} \\
\hline Malaysis & - & 8.1 & 5.8 & 8.9 \\
\hline Thailand & 8.3 & 7.4 & 7.3 & 8.9 \\
\hline Indonesia & 4.0 & 7.8 & 5.8 & 7.1 \\
\hline \multicolumn{5}{|c|}{ Other East Asian } \\
\hline Chian & 2.9 & 7.5 & 9.4 & 10.2 \\
\hline Philippines & 4.9 & 6.1 & 2.0 & 2.4 \\
\hline Vietnam & - & - & - & 7.7 \\
\hline \multicolumn{5}{|l|}{ Other Asian } \\
\hline India & 3.7 & 3.2 & 6.0 & 4.8 \\
\hline
\end{tabular}

Source: UBS Publications 1996, reproduced with permission.

Consistent with the above, assuming that income behaves like a stochastic process and that it is continuous and Markovian, the evolution over time of income distribution can be expressed by the following classical second order partial differential equation:

$$
\frac{\partial f}{\partial t}+\frac{\partial}{\partial s}(\lambda(u-s) f)=\varepsilon \frac{\partial^{2} f}{\partial s^{2}}
$$

where $f$ measures probability density and $s$ measures income. $\lambda$ represents the income adjustment rate, $u$ represents the mean of the distribution in the long run, and $\varepsilon$ represents a diffusion parameter ${ }^{3}$.

\section{Empirical application}

\subsection{Data and Descriptive Statistics}

The empirical analysis employs data on Gross Domestic Product (GDP) per capita of High Performing Asian Economies from 1980 to 2007. Figure 2 illustrates the evolution of the distribution of GDP per capita for the population ${ }^{4}$. A steady growth can be observed, with the South East Asian financial crisis standing out. Table 2

${ }^{3}$ Ref [10] provides a full analysis of this model but in a different context. ${ }^{4}$ Data graphed are yearly means. shows the descriptive of log GDP per capita.

\subsection{Estimation}

The model has been applied to log GDP per capita distribution of the HPAE as a function of time, to estimate the five model parameters ${ }^{5} . u_{0}$ and $u$ denote the initial and long-run mean of the distribution respectively. $\sigma_{0}$ represents the initial standard deviation, $\varepsilon$ represents the diffusion parameter, and $\lambda$ represents the income

${ }^{5}$ The expression representing the time-development of the distribution is:

$f(s, t)=N \mathrm{e}^{\lambda t} \sqrt{\frac{a}{a+\beta}} \mathrm{e}^{-\frac{\left((s-u) \mathrm{e}^{\lambda t}+u-u_{0}\right)^{2}}{2 \sigma_{0}^{2}+\frac{2 \varepsilon}{\lambda}\left(\mathrm{e}^{2 \lambda t}-1\right)}}=N \mathrm{e}^{\lambda t} \sqrt{\frac{a}{a+\beta}} \mathrm{e}^{-\frac{\left(s-u_{t}\right)^{2}}{2 \sigma_{t}^{2}}}$

where

$a=\frac{\sigma_{0}^{2}}{2}$

$\beta=\frac{\varepsilon}{2 \lambda}\left(\mathrm{e}^{2 \lambda t}-1\right)$

$u_{t}=E[f]_{t}=u\left(1-\mathrm{e}^{-\lambda t}\right)+u_{0} \mathrm{e}^{-\lambda t}$

$\sigma_{t}^{2}=\sigma_{0}^{2} \mathrm{e}^{-2 \lambda t}+\frac{\varepsilon}{\lambda}\left(1-\mathrm{e}^{-2 \lambda t}\right)$

$N$ is the normalization constant. Ref [11-14] provide an elaboration, albeit for different contexts. 


\section{Evolution of GDP (Asia)}

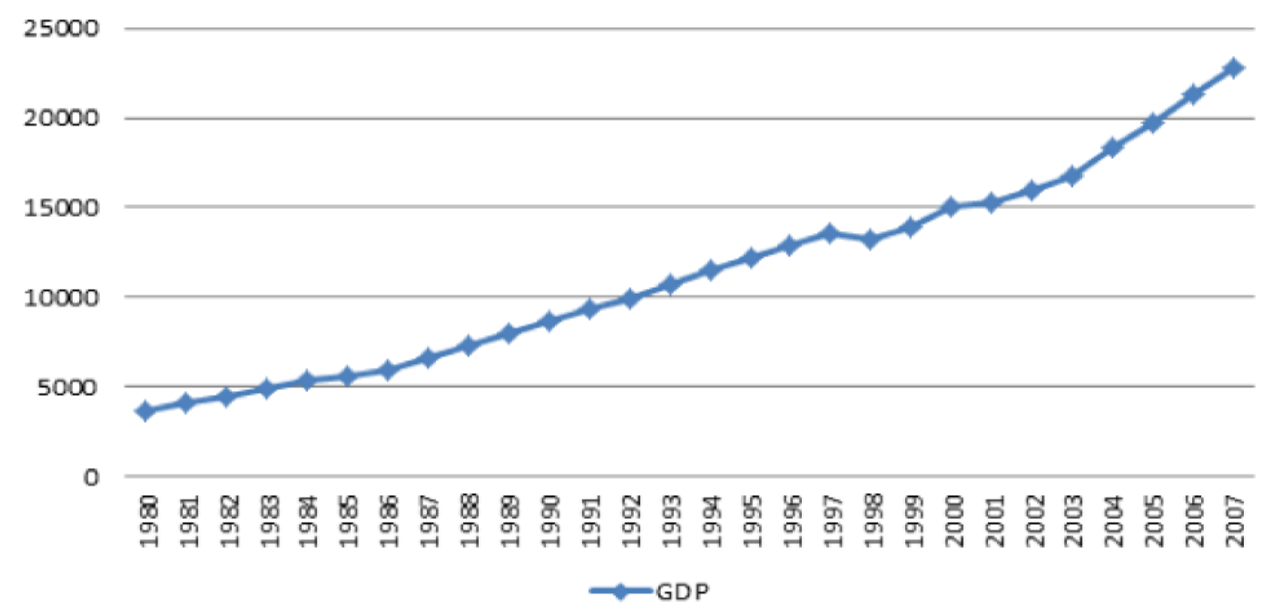

Figure 2. Evolution of GDP.

Table 2. Descriptive of GDP per capita for HPAE from 1980 to 2007.

\begin{tabular}{ccccccc}
\hline & $\mathrm{N}$ & Years & Minimum & Maximum & Mean & Std. Deviation \\
\hline All data & 252 & $1980-2007$ & 5.530 & 10.814 & 8.686 & 1.323 \\
Used for fit & 171 & $1989-2007$ & 6.419 & 10.814 & 9.021 & 1.208
\end{tabular}

adjustment rate. Table 3 reports estimates for the five model parameters.

The value for the income adjustment parameter $\lambda$ is positive as expected. The value for the diffusion parameter $\varepsilon$ is small and positive, likewise conforming to our theoretical predictions. The results predict that if one begins with a normal distribution and allows the model drive the distribution, the distribution variance will tend toward a constant $\lim _{t \rightarrow \infty} \sigma_{t}^{2}=\varepsilon / \lambda$, and concentrated around a mean $u$.

\section{Conclusions}

Our findings have interesting implications for dynamics of the distribution of income across the High Performing Asian Economies. The results suggest that diffusion is a potential technique for the analysis of spatial dynamics of economic growth.

Table 3. Parameter estimates.

\begin{tabular}{cccc}
\hline Parameter & Value & Std Error. & t-value \\
\hline$\lambda$ & 0.014 & 0.011 & 1.221 \\
$u$ & 13.393 & 3.578 & 3.743 \\
$u_{0}$ & 7.781 & 0.125 & 62.250 \\
$\sigma_{o}{ }^{2}$ & 2.251 & 0.084 & 26.680 \\
$\varepsilon$ & 0.010 & 0.009 & 1.143 \\
\hline
\end{tabular}

\section{REFERENCES}

[1] T. Ito and A. Krueger, "Growth Theories in Light of the East Asian Experience," University of Chicago Press, Chicago, 1995.

[2] J. Braude and Y. Menashe, "The Asian Miracle: Was it a Capital-Intensive Structural Change?" Journal of International Trade and Economic Development, Vol. 20, No. 1, 2011, pp. 31-51. doi:10.1080/09638199.2011.538183

[3] A. Charles, G. Fontana and A. Srivastava, "India, China and the East Asian Miracle," Cambridge Journal of Regions, Economy and Society, Vol. 4, No. 1, 2011, pp. 2948.

[4] H. Leung, "Two New Lessons from the Asian Miracles," Journal of the Asia Pacific Economy, Vol. 12, No. 1, 2007, pp. 1-16. doi:10.1080/13547860601083488

[5] J. Kruger, U. Cantner and H. Hanusch, "Total Factor Productivity, the East Asian Miracle, and the World Production Frontier," Review of World Economics, Vol. 136, No. 1, 2000, pp. 111-36.

[6] R. Lucas, "Trade and the Diffusion of the Industrial Revolution," American Economic Journal: Macroeconomics, Vol. 1, No. 1, 2009, pp. 1-25.

[7] D. Levine, "Neuroeconomics?" International Review of Economics, 2011 forthcoming.

[8] J. Hirshleifer, "Evolutionary Models in Economics and Law: Cooperation versus Conflict Strategies," Economic Approaches to Law Series, Vol. 3, 2007, pp. 189-248.

[9] B. McKelvey, "Toward a 0th Law of Thermodynamics: Order-Creation Complexity Dynamics from Physics and 
Biology to Bioeconomics," Journal of Bioeconomics, Vol. 6, No. 1, 2004, pp. 65-96.

doi:10.1023/B:JBIO.0000017280.86382.a0

[10] F. Hashemi, "A Dynamic Model of Size Distribution of Firms Applied to US Biotechnology and Trucking Industries," Small Business Economics, Vol. 21, No. 1, 2002, pp. 1-10.

[11] M.-O. Hongler, R. Filliger and P. Blanchard, "Soluble Models for Dynamics Driven by a Super-Diffusive Noise," Physica A: Statistical Mechanics and Its Applications, Vol. 370, No. 2, 2006, pp. 301-315. doi:10.1016/j.physa.2006.02.036
[12] M.-O. Hongler, H. Soner and L. Streit, L, "Stochastic Control for a class of Random Evolution Models," Applied Mathematics and Optimization, Vol. 49, No. 2, 2004, pp. 113-121.

[13] O. Besson and G. de Montmollin, "Space-Time Integrated Least Squares: A Time-Marching Approach," International Journal for Numerical Methods in Fluids, Vol. 44, No. 5, 2004, pp. 525-543. doi:10.1002/fld.655

[14] F. Hashemi, "An Evolutionary Model of the Size Distribution of Firms," Journal of Evolutionary Economics, Vol. 10, No. 5, 2000, pp. 507-521.

doi:10.1007/s001910000048 